\title{
Remote Mapping of Thermodynamic Index of Ecosystem Health Disturbance
}

\author{
Victor I. Gornyy, Sergei G. Kritsuk, Iscander Sh. Latypov
}

Saint-Petersburg Scientific Research Center for Ecological Safety, Russian Academy of Sciences, Saint-Petersburg, Russia. Email: v.i.gornyy@ecosafety-spb.ru

Received May $4^{\text {th }}, 2010$; revised June $15^{\text {th }}, 2010$; accepted June $18^{\text {th }}, 2010$.

\begin{abstract}
The study of the ecological system (ES) reaction to anthropogenous loading $(A L)$ has been aimed at developing the remote sensing method for quantitative mapping of AL on ES. The analysis of the problem has shown that the main approach for its solution is to assess the amount of entropy induced in ES by AL. The general formalism has been discussed and the thermodynamic index of ES health disturbance (TIEHD- $\left.I_{T}\right)$ has been deduced from the conservation law as a portion of solar exergy spent by ES on the parrying entropy formed in ES due to AL with respect to the total amount of exergy of solar irradiations absorbed by ES. The technique of remote mapping of TIEHD has been developed. The maps of TIEHD and the normalized differential vegetation index (NDVI)- $I_{V}$ have been compiled on the basis of NOAA and EOS satellite data. The qualitative and quantitative analysis exhibited the best sensitivity of TIEHD to AL on ES in respect to NDVI.
\end{abstract}

Keywords: Ecosystem, Thermodynamics, Anthropogenous Loading, Satellite, Index

\section{Introduction}

Quantitative estimation of ES health affected by AL is one of the most challenging problems of environmental state monitoring. In terms of economy remote sensing technology is the most convenient for carrying out operational monitoring of ES reaction to AL.

There have been numerous attempts to create techniques for assessing $\mathrm{AL}$ on $\mathrm{ES}[1,2]$. These techniques are mainly based on the method of induction (from the particular to the general) using numerous quantitative indicators, e.g., indices, describing [1]:

1) the biogeochemical substance and energy cycles;

2) the actual or potential productivity of the ES;

3) the biodiversity of the ecosystems (Species Richness, ES Scarcity, ES Vulnerability);

4) the cultural value of the affected sites;

5) the migration and dispersal of species composition.

W. M. Achten, E. Mathijas, B. Muys [3] based their ES health criteria system on two factors: impact on the ES Structural Quality (Soil fertility, Biomass production, Species diversity) and ES Functional Quality (Soil structure, Vegetation structure, On-site water balance). The authors suggested 22 indicators of AL on ES and the principle of indicators generalization: “...the impact in- dicator scores as the summation of the relative impacts of the different land use activities" [3].

Our analysis of the above mentioned factors leads to the conclusion that this methodology of assessment of $\mathrm{AL}$ on ES cannot be implemented in a real operational mode due to its high complexity and for economic reasons.

There are two different approaches to the solution of scientific problems: microscopic and macroscopic. Statistical thermodynamics, for example, uses the microscopic approach, first, to derive parameters of kinematics and dynamics for each particle of ideal gas, then, to describe the type of chaos, further, to take into account the type of interactions between particles and, finally, to obtain some integrated parameters of the investigated object, e.g. a spatial temperature distribution in the ideal gas. However, the same result (temperature distribution in a solid body) can be more easily obtained using the macroscopic approach. In this case some general parameters of the heat transfer in a solid body (a thermal conductivity, a thermal capacity and a density) are to be measured, followed by a boundary value problem solution of heat transfer using Fourier differential equation. This approach needs much less effort to obtain the same result than the first case. 
The results in $[1,3]$ have been obtained using the microscopic approach (collecting a large number of different indicators for each ES element and compiling a generalized index). Therefore it was found reasonable to make an attempt to create a generalized index of AL on ES using the macroscopic approach. These attempts were made in the framework of the ES thermodynamic theory [4-9].

The main idea of the thermodynamic approach of ES health assessment is to reveal changes of generalized ES thermodynamic parameters caused by AL. Especially noteworthy is the paper concerned mainly with philosophical problems of the thermodynamics of biological organisms by E. D. Schnider and J. J. Kay [5] who formulated nine principles of thermodynamic state of ES. T. Wagendorp et al. reduced these principles to two basic ones (these methods of assessment of ES reaction to AL are discussed in [9]). Their technique includes a description of the structural state of the ES (goal function: maximum exergy ${ }^{1}$ storage) and the function caused by the low entropy system (goal function: maximum exergy dissipation). According to T. Wagendorp et al. only two indices can be used for remote mapping: thermal response number $\left(I_{T R N}\right)$ and solar exergy dissipation $\left(I_{S E D}\right)$, put forward by J. C. Luvall and H. R. Holbo [7] as:

$$
I_{T R N}=\sum_{\tau_{1}}^{\tau_{2}}\left[\left(R_{n} \times \Delta \tau\right) / \Delta T_{s}\right]
$$

where $R_{n}$ is the net incoming radiation; $\Delta \tau=\left(\tau_{2}-\tau_{1}\right)$ is the time interval between two successive remote sensing surveys; $\Delta T_{s}$ is the change of surface temperature $T_{s}$ between moments of time $\tau_{1}$ and $\tau_{2}$.

$$
I_{S E D}=R_{n} / K^{*}
$$

where $K^{*}$ is the net shortwave radiation.

$I_{S E D}$ represents the fraction of the net radiation that is dissipated into a heat - the type of energy with a lower level of exergy. It reflects an exergy degradation and storage in a system [5]. J. C. Luvall and H. R. Holbo mapped $I_{T R N}$ and $I_{S E D}$ applying airborne multispectral survey with the help of a Thermal Infrared Multichannel Scanner (TIMS) [7].

The analysis of these two indices has shown the following deficiencies:

1) these two indices have not been deduced from the basic physical laws, but were suggested empirically;

2) $I_{T R N}$ is the palliative of the thermal inertia (TI) (see [10-14] for details).

The TI reflects the resistance of the surface to the periodic process of heating and cooling. Being a bulk prop-

${ }^{1} E x$-exergy is the maximum work, which ES can perform during the process of reaching the state of equilibrium with the environment [4]. erty, TI does not depend on the time of observation and weather conditions. $I_{T R N}$, being just a characteristics, depends on different natural factors. That is why it is impossible to quantitatively compare $I_{T R N}$ obtained on different dates, even for the same ES.

The best results in the macroscopic approach have been achieved by S. E. Jorgensen and Yu. Svirezhev in their monograph on the general thermodynamic theory of ES [4]. The authors demonstrated that the general thermodynamic measure of AL on ES is the additional production of entropy $\sigma_{\tau}$ taking place in the time interval $\Delta \tau \quad[4]:$

$$
\begin{aligned}
& \sigma_{\tau}=\left[S\left(\tau_{o}+\tau\right)-S\left(\tau_{o}\right)\right]= \\
& {\left[\hat{W}_{f}+\hat{W}_{c h}+\langle P\rangle \Delta \tau-P_{o} \Delta \tau\right] / T ;}
\end{aligned}
$$

where: $S$ is the entropy of ES; $\hat{W}_{f}$ is the total energy loading on $\mathrm{ES} ; \hat{W}_{c h}$ is the total chemical loading on ES; $P$ is the gross primary production measured in mass of carbon per unit area per year: $\left(g\right.$ Carbon $\left./ m^{2} / y r\right)$. The gross primary production is the speed at which an ES stores a given amount of chemical energy as a biomass in a given time interval. $\langle P\rangle$ is the mean gross primary production averaged over the $\Delta \tau$ time of $\mathrm{AL} ; P_{o}$ is the initial gross primary production of ES for the moment of time: $\tau_{o}$, when AL was applied; $T$ is the absolute temperature of ES (assumed constant during all time interval $\Delta \tau) ; \Delta \tau=\tau-\tau_{o} ; \tau$ is the ongoing moment of time.

The analysis of Equation (3) shows that remote measurements of $\hat{W}_{f},\langle P\rangle, P_{0}, T$ are possible to make. However, to determine remotely, the chemical loading $\left(\hat{W}_{c h}\right)$, is very difficult due to a large number of uncertainties making it impossible to use Equation (3) directly. Thus, the main target of this paper is to develop TIEHD that can be mapped remotely, based on general thermodynamic considerations.

The outline of the paper is as follows: Section 2 presents our formalism and derives a general formula for TIEHD. Section 3 deals with materials and methods. Section 4 shows the results for the industrial Urals region, one of the most industrialized and polluted areas of Russia. Discussion and conclusions are presented in Section 5 and Section 6.

\section{General Formalism}

Following the major works concerned with the thermodynamic theory of ES $[4,5,9]$ we suggest that ES and the environment is a supersystem and the environment is much larger than ES. According to Equation (3) AL 
manifests itself as an increase in ES entropy. This is the key factor of the thermodynamic approach to AL assessment. Before discussing the possible techniques of remote mapping of AL on ES it is necessary to additionally emphasize some very important points of the ES thermodynamic theory.

Reference [4] emphasizes the following: "Loss of exergy and production of entropy are two different descriptions of the same reality". The important concept of the "entropy pump" was expressed by Yu. M. Svirezhev [4] The concept of the "entropy pump" assumes that it removes entropy, which normally generates in ES by expending the absorbed exergy of solar radiation. As a result, ES does not accumulate the entropy [4].

To find an indirect assessment of ES degradation under AL one should consider the steady state equilibrium in ES in accordance with [4], i.e. the annual entropy balance of ES is equal to zero ${ }^{2}$. It was shown in [4] that under these assumptions the following equation can be written:

$$
P_{0}-\langle P\rangle=\left(\hat{W}_{f}+\hat{W}_{c h}\right) / \Delta \tau,
$$

The important conclusion resulting from (4) is as follows: the productivity of ES changes due to $A L$. To put it in other words, ES can decrease (or increase in case of fertilization) its biomass productivity, depending on the amount and type of AL. It means that the solar exergy input to ES is spent on:

1) the standard entropy removing from ES (in other case a degradation of biomass of ES must take place);

2) removing of the additional entropy induced by AL;

As a result of AL, the productivity of ES decreases. If the productivity of the ES biomass under AL reaches zero, the further AL increase will result in the degradation of ES biomass.

Taking into account the above mentioned considerations, the exergy balance of ES is as follows:

$$
\hat{E} x_{o}=\hat{E} x_{c}+\hat{E} x_{e}+\hat{E} x_{a}
$$

where $\hat{E} x_{o}$ is the specific flux density of the exergy of solar irradiation assimilated by ES, $W / m^{2} ; \hat{E} x_{c}$ is the portion of $\hat{E} x_{o}$, spent by ES on carbon deposition in ES (a biomass production), $\mathrm{W} / \mathrm{m}^{2} ; \hat{E} x_{e}$ is the portion of $\hat{E} x_{o}$, spent by ES on standard entropy removing from ES, $W / m^{2} ; \hat{E} x_{a}$ is the portion of $\hat{E} x_{o}$, spent by ES on the

${ }^{2}$ It means that ES is not shifted too far from the equilibrium state as a result of $\mathrm{AL}$, and the amount of solar exergy assimilated by ES is enough to remove all entropy produced by AL from ES.

${ }^{3}$ In reality, besides AL disturbing ES, different natural events (for example, forest and grass fires, a mass breading of different insects, etc. can disturb ES as well. parrying of AL, $W / m^{2}$.

Equation (5) shows that solar exergy is spent by ES on a number of processes, such as removing the entropy of biomass (an "entropy pump"), carbon deposition into biomass, AL parrying.

Following [4,9], let's assume the reference ES (background ES), i.e., ES which has not been affected by AL (actually, such ES's are specially preserved natural areas). Then, for the reference (background) ES it follows from Equation (5) that:

$$
\hat{E} x_{o}^{b}=\hat{E} x_{c}^{b}+\hat{E} x_{e}^{b}
$$

where index " $b$ " indicates the background ES.

$\hat{E} x_{a}$ may be expressed after subtracting Equation (5) from Equation (6) as:

$$
\hat{E} x_{a}=\Delta \hat{E} x_{c}+\Delta \hat{E} x_{e}-\Delta \hat{E} x_{o}
$$

where:

$$
\begin{aligned}
\Delta \hat{E}_{o} & =\hat{E} x_{o}^{b}-\hat{E} x_{o} ; \\
\Delta \hat{E} x_{c} & =\hat{E} x_{c}^{b}-\hat{E} x_{c} ; \\
\Delta \hat{E} x_{e} & =\hat{E} x_{e}^{b}-\hat{E} x_{e} ;
\end{aligned}
$$

Taking into account that in this case ES is not shifted far from the equilibrium state we can assume that $\Delta \hat{E} x_{o}$ and $\Delta \hat{E} x_{e}$ are quantities which are much smaller than the other members of Equation (7). Moreover, it is suggested that AL on ES is pared by ES, spending the exergy normally used for carbon deposition. Thus, it is the key moment to assign TIEHD, which leads to the conclusion that when $\mathrm{AL}$ increases, $\Delta \hat{E} x_{c}$ increases accordingly. That is why $\Delta \hat{E} x_{c}$ can be used as the indicator of $\mathrm{AL}$.

TIEHD- $I_{T}$ can be written as:

$$
I_{T}=E x_{a} / \hat{E} x_{o} \approx \Delta \hat{E} x_{c} / \hat{E} x_{o}
$$

According to Equation (8) TIEHD is the portion ( $\left.\hat{E} x_{a}\right)$ of the solar exergy absorbed by ES ( $\left.\hat{E} x_{o}\right)$, spent on the parrying of AL. The right side of Equation (8) makes it possible to calculate TIEHD on the basis of remote (airborne or satellite flown) measurements.

According to Equation (8), for the background ES $I_{T}=0$, because this ES was not affected by AL $\left(\hat{E} x_{a}=\right.$ $0)$. In case $\mathrm{ES}$ is affected by AL: $1>I_{T}>0$. Thus, $I_{T}$ reflects the level of ES health disturbance after $\mathrm{AL}^{3}$.

Concluding this section it is necessary to emphasize the following advantages of TIEHD:

1) unlike the above mentioned indices (see Equations (1) and (2)), which were suggested empirically, TIEHD is derived on the basis of the conservation principle (see Equation (5)); 
2) it can be suggested that TIEHD is more sensitive to $\mathrm{AL}$ than remotely measured vegetation indices, as TIEHD reflects the changes in the physiological process of vegetation (transpiration and photosynthesis).

Therefore, the remote mapping of the rate of carbon deposition and $\hat{E} x_{o}$ provides the possibility to compile a map of TIEHD.

\section{Materials and Methods}

\subsection{Test Site}

The south-eastern Urals region of Russia has been chosen as the test site (the Urals Test Site (UTS)) for TIEHD remote mapping (Figure 1).

The climate of UTS is continental with long cold winters and relatively short and warm summers [15]. There are three biomes within the UTS territory: boreal forest (UTS Western part), South of West Siberian forest steppe, and steppe (UTS Eastern part) [15].

There are two major geomorphologic forms within the UTS territory: Trans-Urals peneplain (UTS Western part) and West Siberian lowland (Eastern part).

The UTS territory lies in one of Russia's oldest industrial regions with a large number of metallurgical, metalworking, engineering, and chemical enterprises. The biggest industrial centers are the cities of Chelyabinsk, Karabash, Kopeisk, Miass, Zlatoust (see Figure 1).

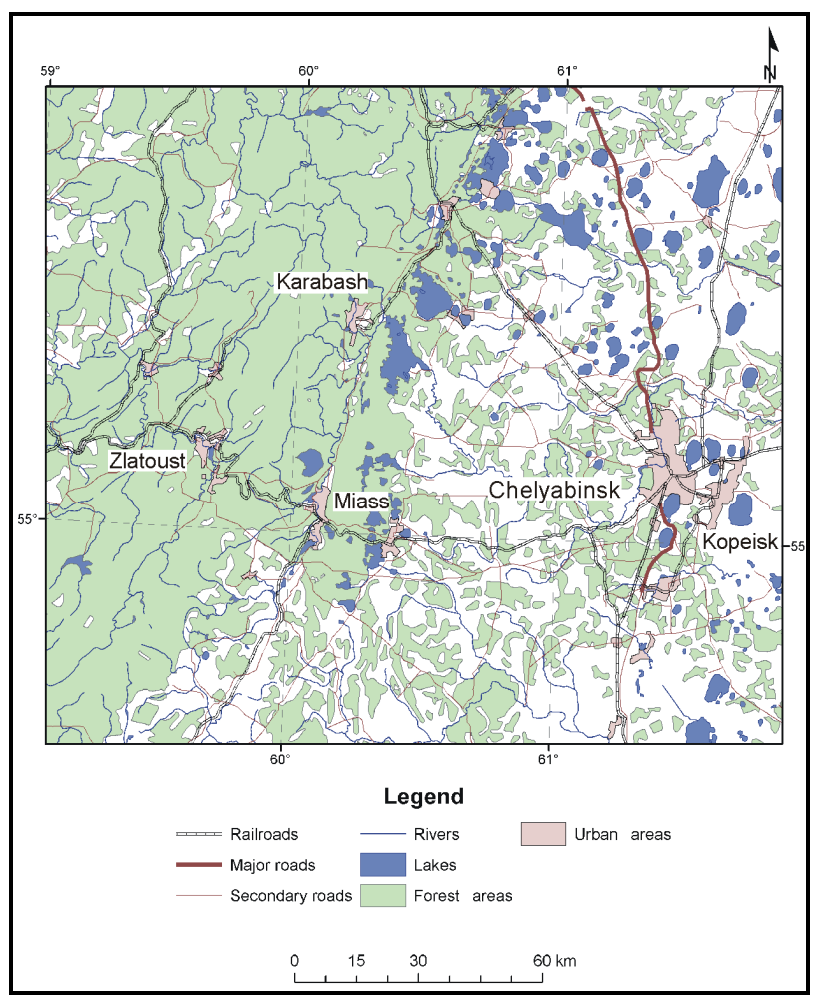

Figure 1. The schematic map of the UTS.
The main requirements for TIEHD remote mapping technique verification were the following: the total range of $\mathrm{AL}$ on $\mathrm{ES}$ has to be varied from maximum to minimum; the test site ES has to be homogeneous enough and the $\mathrm{AL}$ source has to be unique.

The city of Karabash in Chelyabinsk Oblast' is the one of such places within UTS (Figure 1).

The city of Karabash is located in a mountainous taiga area. The main species of the forests are spruce, silver fir and an admixture of pines, mountain ashes and junipers. The soil is mountainous podzol. The main wind direction is latitudinal. The city is situated in the depression of the surface relief.

The copper smelting plant was built in the city of Karabash early in the 19th century. Besides, the smelting of complex sulfide ores started at the beginning of the 20th century. As a result, the surrounding ES was significantly affected by this enterprise at the end of the 20th century. For example, during the peak of the Karabash enterprise production (till 1989) about 160-180 thousand tons of pollutants in the form of smoke, dust and gases were thrown out into the atmosphere annually. About $90 \%$ of it was sulfur dioxide, the others being lead, copper, zinc, arsenic, as well as carbon oxide, nitrogen dioxide, etc. 12 million tons of harmful substances have been thrown out into the atmosphere during all the time of the industrial complex activity. As a result, ES around the city of Karabash has been affected by the hard AL during a long time period. This is illustrated in the map of NDVI- $I_{V}$ (see Figure 5). The broad area of dead vegetation can be observed inside and around the city of Karabash.

\subsection{Data}

Terra(MODIS) satellite data were used to calculate $\hat{E} x_{o}$ (Equation (9), Table 1).

\section{3. $\hat{E} x_{o}$ Mapping}

The $\hat{E} x_{o}$ can be measured remotely using the technique described by S. Yorgensen and Yu. Svirezhev [4]:

$$
\begin{aligned}
& \hat{E} x_{o}=\int_{\Omega} Q^{o u t}(v) \operatorname{Ln}\left[Q^{\text {out }}(v) / Q^{\text {in }}(v)\right] d v+R= \\
& R[1+\bar{\alpha}(K u+\ln \bar{\alpha}-1) /(1-\bar{\alpha})] ;
\end{aligned}
$$

where $Q^{\text {out }}, Q^{\text {in }}$ are the outgoing and the ingoing specific densities of solar irradiation fluxes respectively, $W / m^{2} ; \quad v$ is the frequency of light spectrum; $\Omega$ is the total measured spectral interval; $K=\sum_{i=1}^{n} p_{i} \log \left(p_{i} / p_{i}^{0}\right)$ is Kullback's measure; $p_{i}^{0}, p_{i}$ probabilities before and 
Table 1. Satellite data, used for the map of TIEHD compilation.

\begin{tabular}{ccccc}
\hline Date & $\begin{array}{c}\text { Time } \\
\text { GMT, } \\
\text { hrs:min:s }\end{array}$ & Satellite & Instrument & Channels \\
& 07:00:00 & NOAA-18 & AVHRR & 4,5 \\
& $07: 00: 00$ & Terra & MODIS & $1-7,31,32$ \\
June, 4, & $08: 50: 00$ & Aqua & MODIS & $1-7,31,32$ \\
2009 & $15: 23: 00$ & NOAA-17 & AVHRR & 4,5 \\
& $18: 15: 00$ & Terra & MODIS & 31,32 \\
& $22: 00: 00$ & Aqua & MODIS & 31,32 \\
\hline June,5, & $01: 31: 00$ & NOAA-15 & AVHRR & 4,5 \\
& $05: 35: 00$ & NOAA-17 & AVHRR & 4,5 \\
& $07: 45: 00$ & Terra & MODIS & $1,2,31,32$ \\
& $07: 55: 00$ & Aqua & MODIS & $1,2,31,32$ \\
& $21: 25: 00$ & Aqua & MODIS & 31,32 \\
\hline
\end{tabular}

after the interaction respectively; $R$ is the radiation balance at ES surface, $W / m^{2} ; \quad \bar{\alpha}=Q^{\text {out }} / Q^{\text {in }}$ is the surface albedo.

For the Terra(MODIS) satellite data, the surface albedo can be mapped by using the standard MODIS Level 1B product, described in [16].

The result of mapping of $\hat{E} x_{o}$ inside the UTS has been shown in Figure 2.

\subsection{Mapping of Carbon Deposition in ES}

The portion of $\hat{E} x_{o}$ spent by ES on carbon deposition $\hat{E} x_{c}$ directly depends on the amount of water evaporated by ES [4]. It is necessary for vegetation to dissipate 278 $K J$ of heat for $1 \mathrm{~g}$ of carbon deposition as a biomass [4]. Hence, the following formula can be presented as:

$$
\hat{E} x_{c}=a \times b \times \bar{V}=3.66 \times \bar{E}
$$

where: $\bar{E}$ is the specific daily mean average evaporation rate, $\mathrm{m}^{3} /\left(\mathrm{m}^{2} * \mathrm{~s}\right) ; a=1 / 879,\left(\mathrm{~kg}\right.$ of carbon $/ \mathrm{m}^{3}$ of $\mathrm{H}_{2} \mathrm{O}$ ), the carbon/water factor (ES has to evaporate 879 $\mathrm{m}^{3}$ of water to assimilate $1 \mathrm{~kg}$ of carbon); $b$ is the factor of specific energy of carbon assimilation $\left(278 * 10^{6} \mathrm{~J} /(\mathrm{kg}\right.$ of (carbon)).

The method used for $\bar{E}$ remote mapping is based on TI approach [11-14,17-20] (Figure 4). This approach uses the daily variation of the land surface temperature $T_{s}$ as a mathematical model, taking into account the basic factors affecting $T_{s}$ formation. Our model [11] assumes the following: the meteorological conditions and concentration of optically active gases in the atmosphere within

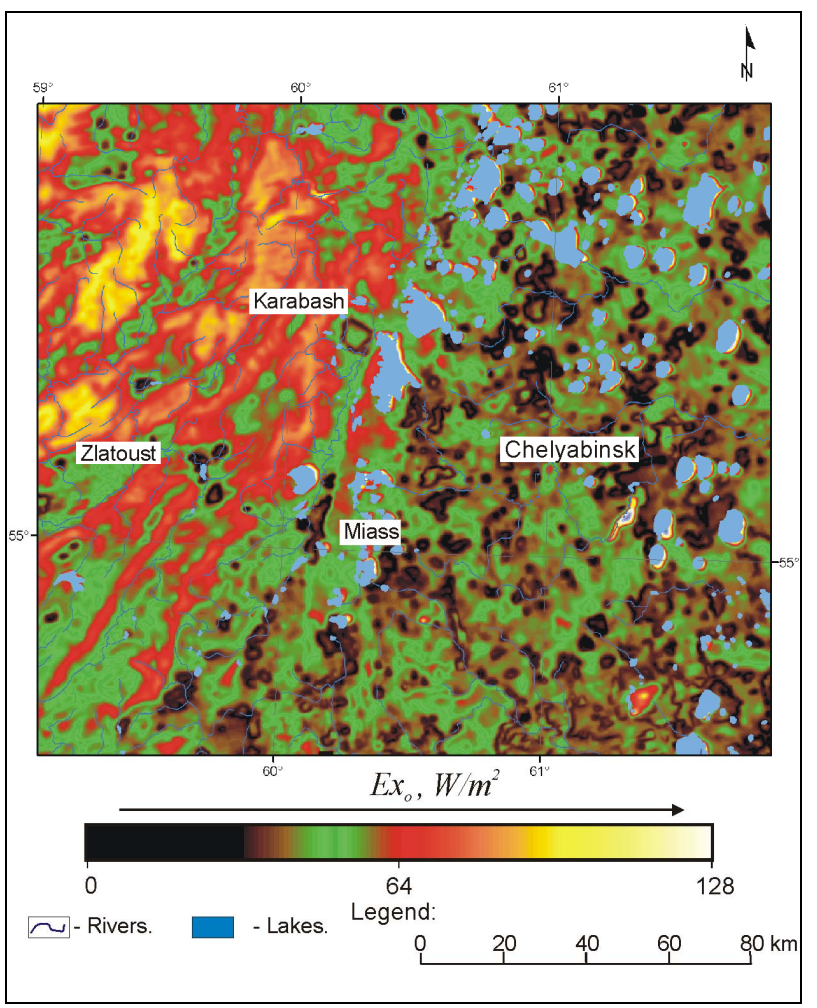

Figure 2. The map of $\hat{E} x_{o}$, compiled for the territory of UTS on the basis of Terra(MODIS) satellite data.

the whole study area are identical; emissivity, albedo of land surface, and TI do not vary during the whole period of the satellite observations. To determine $\bar{E}$, we use the results of a thermal \& multispectral satellite survey conducted for several days under stable meteorological conditions in the absence of rainfall with the aim to characterize the daily $T_{s}$ dynamics more precisely. Moreover, $\bar{E}$ mapping is based on the following parameters of routine meteorological observations, involved in the mathematical model of $T_{s}$ :

1) total solar radiation,

2) air temperature, air moisture, and wind velocity at a height of $2 m$ above the surface,

3) atmospheric pressure,

4) cloudiness.

To solve the inverse problem the look-up table method was used, following J. C. Price [18]. Mathematical simulations of $T_{s}$ were performed for all possible combinations of TI, $\bar{E}$, a heat flux and an albedo, i.e., the "library" of $T_{s}$. Then the measured $T_{s}$ values were compared with the simulated quantities. The values sought $\bar{E}$ were deduced in accordance with the assigned fitting criteria of the measured and simulated $T_{s}$ values. When this algorithm is used, the systematic error of the inverse problem solution for $\bar{E}$ (Figure 4) equals $0.3 \mathrm{~mm} /$ 


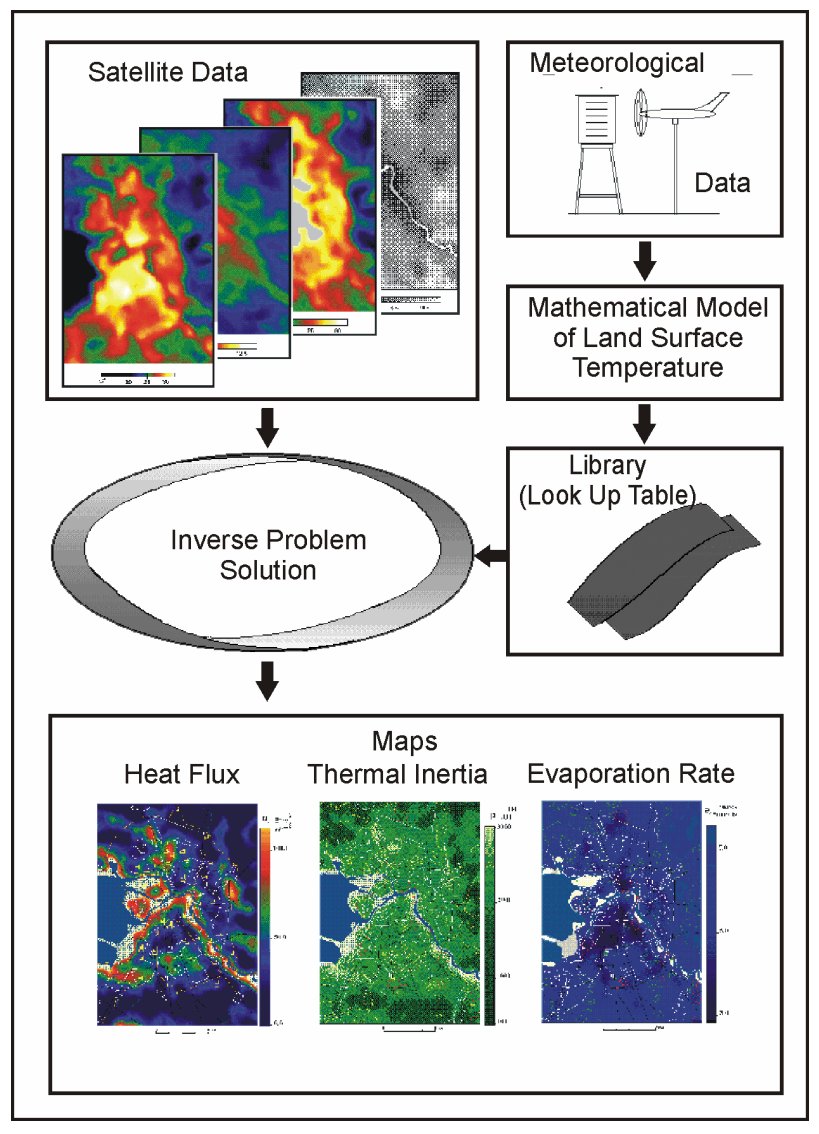

Figure 3. The algorithm of TI, $\bar{E}$ and the heat flux mapping on the basis of multiple satellite survey and meteorological observation data.

$\left(m^{2} * d a y\right)$, while the root-mean square error equals 0.1 $\mathrm{mm} /\left(\mathrm{m}^{2} *\right.$ day $)$.

The analysis of $\bar{E}$ spatial distribution (Figure 5) shows the above described differences in ES between Western and Eastern parts of UTS. In the framework of the Western part one can observe more intensive $\bar{E}$, than those of the Eastern part. After that $\hat{E} x_{c}$ has been calculated according to Equation (8).

Finally, it should be stressed that the TI-approach based algorithm was used because it allowed the remote mapping of the daily mean averaged evaporation rate $\bar{E}$. However, by now the maximum spatial resolution of satellite scanners that enable multiple daily surveys in the infrared-thermal spectral band has not been more than 1 $\mathrm{km}$. That is why TI approach can't be used for more detailed mapping with the help of, e.g. Landsat TM (ETM+) or ASTER infrared-thermal \& multispectral images. In this case the methods described in $[6,19,20]$ are preferable. However, the evaporation rate obtained by using single survey methods is not daily mean averaged and reflects the moment of time during which the satellite

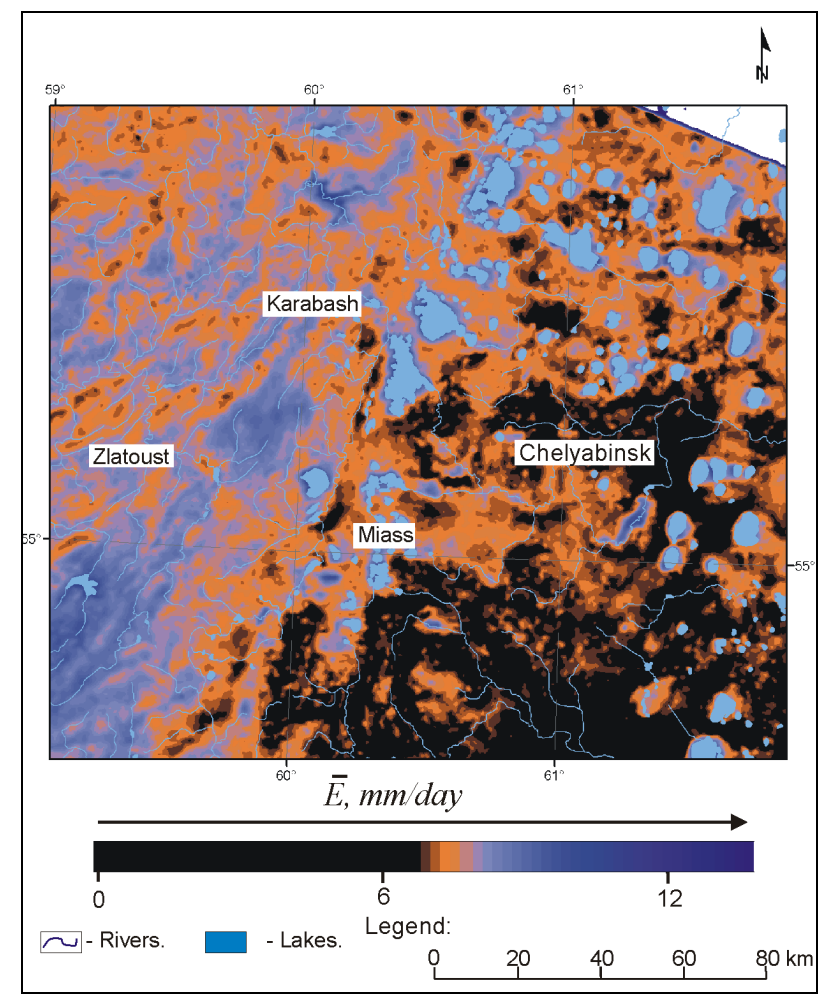

Figure 4. The map of $\bar{E}$, compiled by using the Terra(MO DIS) and NOAA(AVHRR) satellite data.

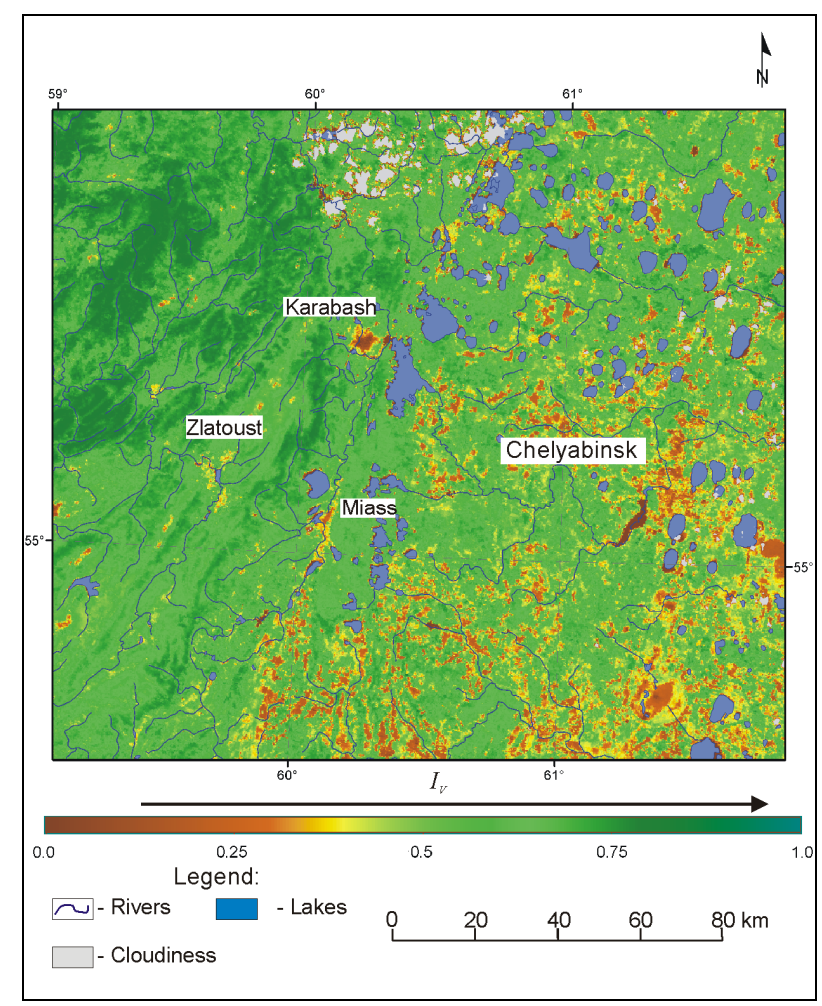

Figure 5. The map of NDVI for the UTS, according the Terra (MODIS) satellite survey on June 4, 2009. 
survey has been done.

As it follows from the Equation (8), if one knows the spatial distributions of $\hat{E} x_{c}$, as well as, $\hat{E} x_{o}$, the $I_{T}$. can be calculated.

\section{Results}

Due to the big difference between ESs of the Western and Eastern parts of UTS the TIEHD calculation was carried out separately for each part according to the right part of Equation (8). The result is shown in Figure 6. The boundary between the Western and Eastern parts is marked by the white stroke-dashed line. This boundary was plotted on the basis of the visual interpretation of satellite data. For the best accuracy it should be plotted with the help of unsupervised classification of satellite data. Two areas of background ES's have been selected for each part of the UTS (both Western and Eastern) (shown by white dotted lines in Figure 6) as the areas of maximal $\bar{E}$. Calculations of TIEHD were made for each part of the UTS separately according to the background ES (unaffected by AL).

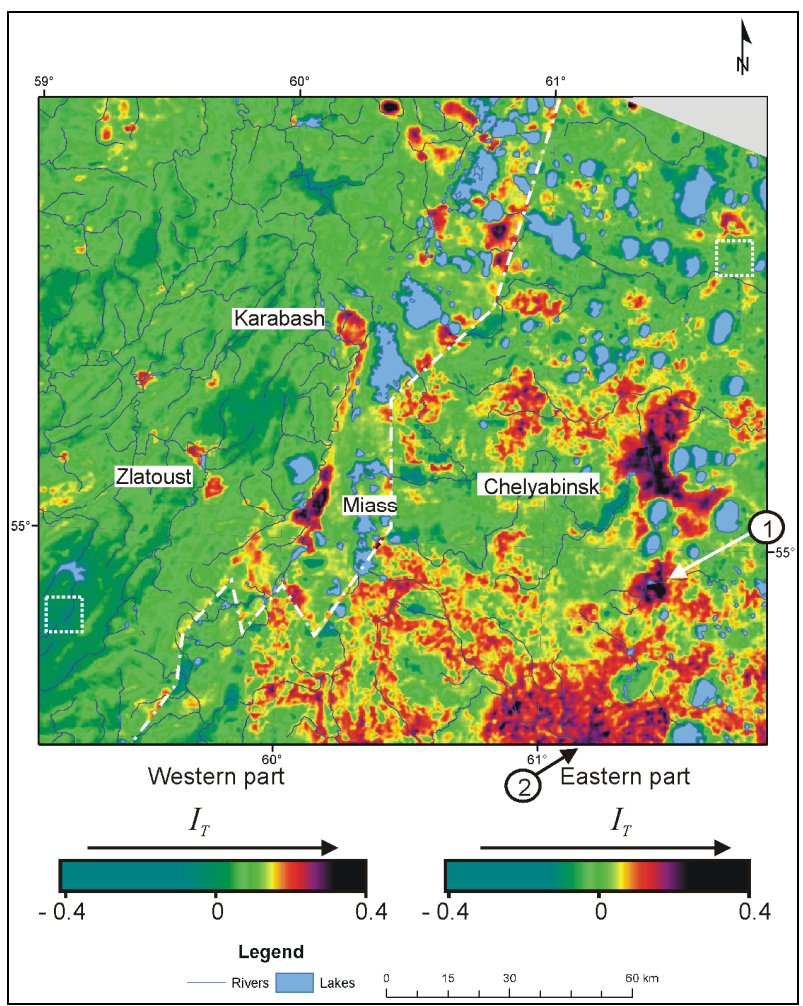

Figure 6. The map of TIEHD compiled for the UTS on the basis of satellite data. The boundary between the Western and Eastern ESs is marked by the white stroke-dashed line. The white dotted line marks background ESs for Western and Eastern parts of UTS. 1. The Korkino Open Cast for brown coal mining; 2. The location of Yuzhno-Ural'skaya and Troitskaya Electricity Power Plants.

\section{Discussion}

The visual analysis of the set of maps (Figure 6), (Figure 1) and (Figure 5) leads to the following conclusions:

1) the urban and industrial areas are characterized by a high level of TIEHD;

2) the areas of high TIEHD, which indicate urban and industrial areas, are bigger than the areas of low NDVI, indicating the same sources of AL.

Besides the visual analysis, the comparison of TIEHD and NDVI sensitivity to AL on ES's for the territory around the city of Karabash was made quantitatively (for the Western part of the UTS only). The water surfaces of lakes, as well as clouds were masked on the TIEHD and NDVI maps. After that, the normalized indices were calculated and plotted in Figure 7 as Normalized TIEHD: $\left(I_{T}\right) /\left[\left(I_{T}\right)_{\max }\right]$ and Normalized Complementary NDVI: $\left(1-I_{V}\right) /\left[\left(1-I_{V}\right)_{\max }\right]$. These indices have been averaged inside the Western semi-circumference for each pixel of the radius, plotted from the center of the city of Karabash. As a result, Figure 7 indicates that the Normalized TIEHD varies from $I_{T}=1.0$ at the radius of $R \approx 2 \mathrm{~km}$ from the Karabash city center up to $I_{T} \approx 0.4$ for the radius of $R=11 \mathrm{~km}$ from that center. At the same time the Normalized Complementary NDVI has maximum $\left(I_{V}=1.0\right)$ exactly at the center of the city of Karabash and the minimum $\left(I_{V}=0.36\right)$ at the radius of $R \approx 12$ $\mathrm{km}$.

Let's assume that the width of the indice's peak at the

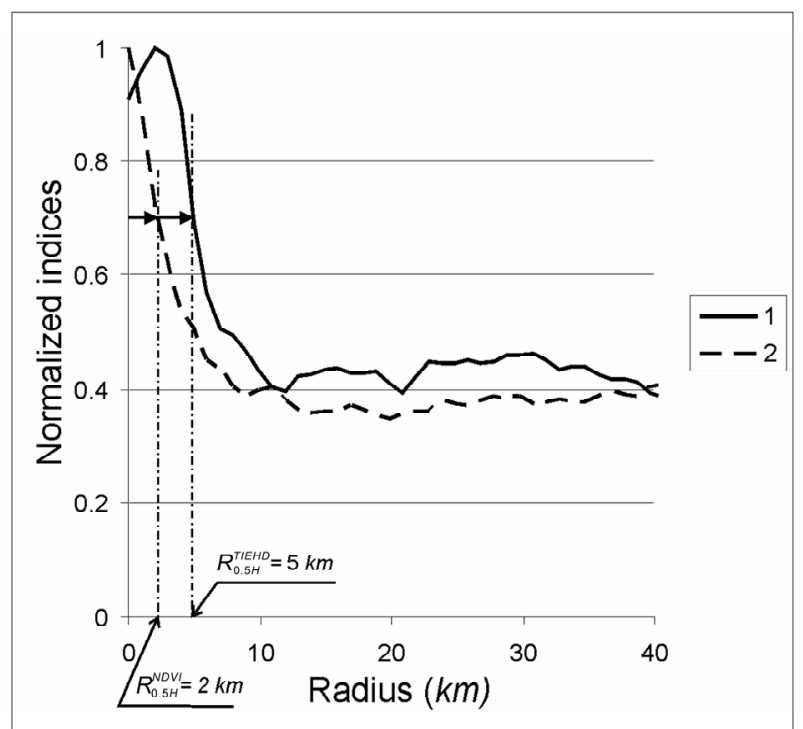

Figure 7. Comparison of Normalized TIEHD and the Normalized Complementary NDVI sensitivity to the AL on ES around the city of Karabash, the UTS. 1. Normalized TIEHD: $\left(I_{T}\right) /\left[\left(I_{T}\right)_{\max }\right]$; 2. Normalized Complementary NDVI: $\left(1-I_{V}\right) /\left[\left(1-I_{V}\right)_{\max }\right]$. 
half of the peak's height $\left(2 R_{0.5 H}\right)$ indicates the sensitivity of indices to AL. In this case, for the city of Karabash, according the Normalized TIEHD the $2 R_{0.5}^{T I E H D}=10 \mathrm{~km}$ (Figure 7), while for the Normalized Complementary NDVI such width $2 R_{0.5 H}^{N D V I}=4 \mathrm{~km}$ (Figure 7). This leads to the conclusion that the sensitivity of TIEHD to AL is 2.5 times better, compared to NDVI.

The highest sensitivity of TIEHD to Al on ES can be explained by the following considerations. TIEHD is calculated using such characteristics of vegetation physiological processes as photosynthesis activity and quality, as well as water transpiration by leaves. However, the vegetation index reflects the presence of chlorophyll in ES. That is why, it can be suggested that the vegetation index records the dramatic stage of vegetation degradation, when the vegetation has lost chlorophyll (resulting from forest cuttings, forest and steppe fires or vegetation death after acid industrial precipitations, as in the case of the city of Karabash, etc.).

The comparison between TIEHD inside the Western part of UTS (Figure 6) and TIEHD inside the Eastern part of UTS shows a big difference, with the Eastern part having the highest TIEHD. It can be explained by the landscape difference of these two parts, as well as by different anthropogenic activity. As can be seen in Figure 2, the Western part of the UTS is covered by forest, while the Eastern part is mainly covered by cultivated fields. The map of TIEHD was compiled for the beginning of summer. For the agriculture $\&$ climatic zone of UTS it is the time with no vegetation on the surface of fallow fields. As a result, there are areas of the bare soil here, whose evaporation rate is much lower than that of the forested area. Thus, TIEHD of the cultivated area for the beginning of June is much bigger than TIEHD of the forested area which is not affected by AL.

The big urban and industrial area around the city of Chelyabinsk is characterized by high TIEHD, resulting from very big AL on ES. Two more areas of high TIEHD were investigated additionally. For example, the area of high TIEHD, situated to the south of the city of Chelyabinsk ( 1 in Figure 6) indicates the giant Korkino Open Cast. Its depth reaches $500 \mathrm{~m}$. The Open Cast supplies Yuzhno-Ural'skaya and Troitskaya Electric Power Plants with brown coal. The total power of the Electric Power Plants is $\sim 3000 \mathrm{MW}$. One of the possible reasons for a very big area of high TIEHD at the Southern border of UTS ( 2 in Figure 6) is the pollution of ES resulting from the smoke of these Electric Power Plants.

Unlike this situation, water basins (lakes, water ponds, etc) are surrounded by the zones of very low TIEHD (Figure 6), as, according to Russia's legislation the zones surrounding water basins are territories specially protected from AL. It is one of the explanations of the above mentioned phenomenon.

\section{Conclusions}

To summarize, the major regularities of thermodynamic reply of $\mathrm{ES}$ on $\mathrm{AL}$ have been presented and discussed. Based on the conservation law of exergy fluxes inside ES, it has been shown that after some simple assumptions TIEHD can be represented as a portion of solar exergy spent by ES on the parrying entropy formed in ES due to AL with respect to the total amount of exergy of solar irradiations absorbed by ES. It has also been shown that TIEHD may be mapped on the basis of remote (airborne or satellite flown) measurements made in the visible, nearest infrared and infrared-thermal spectral bands by optic \& electronic scanners.

We have chosen the Southern-Eastern Ural region of Russia as the Test Site and compiled the map of TIEHD by using NOAA and EOS satellite data. The preliminary analysis exhibits a better sensitivity of TIEHD to AL on ES than the NDVI.

It can be concluded that the macroscopic approach (it was used for the TIEHD compilation) is simpler and less expensive for the satellite monitoring of AL on ES than the microscopic approach based on big a number of different indices and their generalization.

The further directions extending our research results include, in particular, the investigation of TIEHD seasonal dynamic and the detailed ground truth of TIEHD maps.

\section{Acknowledgements}

This publication is an output from the research project Remote sensing methods development for a quantitative estimation of ES reply on AL No 01.2.007.08 731 funded by the Russian Academy of Sciences. We thank the anonymous referee for the constructive criticism and comments.

\section{REFERENCES}

[1] B. P. Weidema, "Physical Impacts of Land Use in Product Life Cycle Assessment," 2001. http://www.lca-net. com/publications/older/

[2] S. E. Jorgensen, R. Costanza, F. L. Xu, (Eds.) "Handbook of Ecological Indicators for Assesment of Ecosystem Health," Taylor \& Frances, 2005.

[3] W. M. J. Achten, E. Mathijs and B. Muys, "Proposing a Life Cycle Land Use Impact Calculation Methodology," Proceedings of 6th International Conference on LCA in the Agri-Food Sector, Zurich, 12-14 November 2008.

[4] J. S. Jorgensen and Yu. M. Svirezhev, "Towards a Thermodynamic Theory for Ecological Systems," Elsever, Oxford, 2004. 
[5] E. D. Schnider and J. J. Kay, "Life as a Manifestation of the Second Law of Thermodynamics," Mathematical and Computer Modelling, Vol. 19, No. 6-8, 1994, pp. 25-48.

[6] S. M. Moran, "Chapter 8. Thermal Infrared Measurements as Indicator of Plant Ecosystem Health," In: D. A. Quatochi and J. C. Luvall, Eds., Thermal Remote Sensing in Land Surface Processes, Tailor and Frances, London, 2004, pp. 257-282.

[7] J. C. Luvall and H. R.Holbo, "Measurements of Short Term Thermal Response of Coniferous Forest Canopies Using Thermal Scanner Data," Remote Sensing of Environment, Vol. 27, No. 1, 1989, pp. 1-10.

[8] R. D. Jackson, "The Crop Water Stress Index: A Second Look," Proceedings of International Conference on Measurment of Soil and Plant Water Stress, Utah State University, July 1987, pp. 87-92.

[9] T. Wagendorp, H. Gulinck, P. Coppin and B. Muys, "Land Use Impact Evaluation in Life Cycle Assessment Based on Ecosystem Thermodynamics," Energy, Vol. 31, No. 1, 2006, pp. 112-125.

[10] K. Watson, L. C. Rowan and T. V. Offield, "Application of Thermal Modelling in Geologic Interpretation of IR Images," Proceedings of 7th International Symposium on Remote Sensing of Environment, Ann Arbor, Michigan, 1971, pp. 2017-2041.

[11] V. I. Gornyy, B. V. Shilin and G. I. Yasinskii, "Teplovaya aerokosmocheskaya s'emka (Thermal Airborne and Satellite Flown Survey)," in Russian, Nedra, Moscow, 1993.

[12] Y. Xue and A. P. Cracknell, "Advanced Thermal Inertia Modeling," International Journal of Remote Sensing, Vol. 16, No. 3, 1995, pp. 431-446.

[13] A. P. Cracknell and Y. Xue, "Thermal Inertia Determina- tion from Space-A Tutorial Review," International Journal of Remote Sensing, Vol. 17, No. 3, 1996, pp. 431-461.

[14] V. I. Gornyy and S. G. Kritsuk, "Possibility of Mapping Physiographic Zones by Thermal Survey from Space," Doklady Earth Sciences, Vol. 411A, No. 9, 2006, pp. 1473-1475.

[15] A. I. Levit, "Yuzhnyi Ural: geografiya, ecologiya, prirodopol'zovanie (South Ural: Geography, Environment, Landuse)," in Russian, Yuzhno-Ural'skoe, izdatel'stvo, 2005.

[16] J. Xiong, G. Toller, V. Chiang, J. Sun, J. Esposito and W. Barnes, "MODIS Level 1B Algorithm Theoretical Basis Document. Version 3, Prepared for: National Aeronautics and Space Administration," 2005. http://mcst.gsfc.nasa. gov/uploads/files/documents/M1058.pdf

[17] G. Boulet, A. Chehbouni, I. Braud, M. Vauclin, R. Haverkamp and C. Zammit, "A Simple Water and Energy Balance Model Designed for Regionalization and Remote Sensing Data Utilization," Agricultural and Forest Meteorology, Vol. 105, No. 1-3, 2000, pp. 117-132.

[18] J. C. Price, "On the Use of Satellite Data to Infer Surface Fluxes at Meterological Scales," Journal of Applied Meteorology, Vol. 21, No. 8, 1982, pp. 1111-1122.

[19] H. A. M. Thunnissen and G. J. A. Nieuwenhuis, "A Simplified Method to Estimate Regional 24-h Evapotranspiration from Thermal Infrared Data," Remote Sensing of Environment, Vol. 31, No. 3, 1990, pp. 211-225.

[20] A. Vidal and A. Perrier, "Analysis of a Simplified Relation for Estimating Daily Evapotranspiration from Satellite Termal IR Data," International Journal of Remote Sensing, Vol. 10, No. 8, 1989, pp. 1327-1337. 